\title{
Increased Neurogenesis in Adult mCD24-Deficient Mice
}

\author{
Richard Belvindrah, Geneviève Rougon, and Geneviève Chazal
}

Neurogenèse et Morphogenèse dans le développement et chez l'adulte/Institut de Biologie du Développement de Marseille, Centre National de la Recherche Scientifique, Institut National de la Santé et de la Recherche Médicale, Université de la Méditerranée, Campus de Luminy, 13288 Marseille, France

mCD24, a glycosylphosphatidylinositol-anchored highly glycosylated molecule, is expressed on differentiating neurons during development. In the adult CNS, its expression is restricted to immature neurons located in two regions showing ongoing neurogenesis: the subventricular zone (SVZ) of the lateral ventricle pathway and the dentate gyrus (DG) of the hippocampal formation. Here, combining bromodeoxyuridine (BrdU) and proliferating cell nuclear antigen labelings we confirmed that mCD24 is expressed on proliferating cells. To determine whether the inactivation of the molecule may affect adult neurogenesis, we analyzed the phenotype of mCD24-deficient mice (mCD24-/-). We labeled cells in S-phase with a pulse, a long, or a cumulative administration of BrdU and analyzed cells in different zones according to their dividing rate (rapid and slow) both in the control and mCD24-/-. We found a significant increase in the number of rapid (in the SVZ and the DG) and slow (in the SVZ) proliferating cells. Cumulative assays revealed a global reduction of the total cell cycle duration of rapidly proliferating precursors of SVZ. We investigated the fate of supernumerary cells and observed an increased number of apoptotic cells (terminal deoxynucleotidyl transferasemediated biotinylated UTP nick end labeling) in the mutant SVZ. Furthermore, we found no difference in the size of the olfactory bulb between wild-type (WT) and mutant mice. In support, mCD24 deletion did not appear to affect migration in the migratory stream. A comparison of the organization of migrating precursors between WT and mCD24 -/-, both in vivo at the optic and electron microscopic levels and in SVZ cultured explants, did not show any changes in the arrangement of neuroblasts in chain-like structures.

Altogether, our data suggest that $\mathrm{mCD} 24$ regulates negatively cell proliferation in zones of secondary neurogenesis.

Key words: mCD24; proliferation; adult neurogenesis; neural progenitor; rostral migratory stream; apoptosis
It is now well documented that throughout adult life, the brain of rodents (Altman and Das, 1965), primates, and humans (Eriksson et al., 1998; Gould et al., 1998) retains a neurogenic population of cells. Cell division persists mainly in two regions: the subventricular zone (SVZ) of the lateral ventricle and the dentate gyrus (DG) of the hippocampal formation (Hinds, 1968; Altman, 1969; Lois and Alvarez-Buylla, 1993; Luskin, 1993). In the SVZ, newborn cells migrate from the wall of the lateral ventricle into a long and well defined pathway, the rostral migratory stream (RMS), to reach the olfactory bulb $(\mathrm{OB})$, where they differentiate into granular and periglomerular neurons (Doetsch and Alvarez-Buylla, 1996; Jankovski and Sotelo, 1996). On the contrary, in the DG, new neurons generated at the border between the hilus and the granule cell layer differentiate locally in the neuronal circuitry (Gould et al., 1998).

The properties of these adult neural progenitors are primarily investigated in perspective to renew neurons by grafting them in damaged CNS or by reactivating endogenous factors. To be able

\footnotetext{
Received Nov. 14, 2001; revised Feb. 8, 2002; accepted Feb. 14, 2002.

This work has been supported by institutional grants from the Centre National de la Recherche Scientifique, the European Community program (Grant QLRT 199930911), Association pour la Recherche sur le Cancer Grants ARC 4401 (G.C.) and ML/MLD/CM-P01/4 (R.B.), Hoechst Marion Roussell, and Ministère de l'Education Nationale de la Recherche et de la Technologie Grant 982157 (R.B.). We thank Jean-Paul Chauvin for technical help and Dr. P. J. Nielsen for the gift of the mCD24 mutant mouse. We also acknowledge Drs. H. Cremer, C. FaivreSarrailh, and J. Falk for their helpful comments on this manuscript.

Correspondence should be addressed to Geneviève Chazal, Neurogenèse et Morphogenèse dans le développement et chez l'adulte/Institut de Biologie du Développement de Marseille, Campus de Luminy, Case 907, 13288 Marseille cedex 9, France. E-mail: chazal@ibdm.univ-mrs.fr.

Copyright (C) 2002 Society for Neuroscience $\quad 0270-6474 / 02 / 223594-14 \$ 15.00 / 0$
}

to manipulate this adult cell population, it is fundamental to understand the factors that maintain and regulate its proliferation and differentiation throughout adult life.

We have shown that mCD24, a glycosylphosphatidylinositolanchored molecule, is expressed on BrdU + cells in zones of adult neurogenesis (Chazal et al., 2000). Thus, we suspected that this molecule could be a candidate implicated in the regulation of cell proliferation precursors. mCD24 (mouse Cluster of Differentiation 24) is a small protein of 30 amino acids exhibiting several highly glycosylated tissue-specific isoforms that was originally described as a pre-B lymphocyte marker (Kay et al., 1991; Wenger et al., 1991). mCD24 was also described in other cell types such as T-cells (Crispe and Bevan, 1987), regenerating muscle cells (Figarella-Branger et al., 1993), or neurons (Rougon et al., 1991; Kadmon et al., 1992). Among the three isolated genes susceptible to encode mCD24, only one has been shown to be expressed (Wenger et al., 1991). It has been demonstrated that in the developing mouse nervous system its expression is spatiotemporally regulated (Nedelec et al., 1992; Shirasawa et al., 1993) and is restricted to the neurons when they are migrating and differentiating toward their final destination (Kuchler et al., 1989). Interestingly, in adult CNS, mCD24 expression is maintained only in zones of secondary neurogenesis (Calaora et al., 1996). Altogether, these data make $\mathrm{mCD} 24$ as a developmentally regulated molecule implicated in neuronal differentiation.

The function of mCD24 has not yet been clearly demonstrated. However, different in vitro studies suggested that it could be involved in cell adhesion and signaling. Indeed, when presented on transfected cells as a monolayer substratum, mCD24 inhibits 
neurite outgrowth and branching of peripheral nervous system and CNS neurons (Shewan et al., 1996).

Here, using mCD24-deficient mice (mCD24-/-) (Nielsen et al., 1997), we analyzed the effects of its deletion on the migration and proliferation of neuronal precursors in the SVZ and in the DG. We did not find any perturbation in the chain-like migrating neuroblasts in mCD24-/- mice. However, we found an increase in the total number of both rapidly (in the SVZ and in the DG) and slowly proliferating cells (in the SVZ). In addition, by BrdU cumulative labeling and proliferating cell nuclear antigen (PCNA) staining, we showed a global reduction of total cell cycle length (Tc) in mCD24-/- mice. These results suggest a role of mCD24 in the maintenance of precursor cells in a quiescent state or in the initiation of differentiating events of differentiation.

\section{MATERIALS AND METHODS}

Animals. All analyses were performed on a C57BL/6 background in male mice at $60 \mathrm{~d}$ postnatal (P60). Construction of mCD24 targeted mice have been described previously (Nielsen et al., 1997). Briefly, inactivation of the $m C D 24$ gene was obtained by replacing the promoter and first exon by a neomycin resistance expression cassette in mouse embryonic stem cells by homologous recombination. Chimeric offspring carrying the targeted $m C D 24$ mutation were then mated to C57BL/6 mice, and germline transmission of the mutation was obtained.

Immunohistochemistry. Control and mutant mice were deeply anesthetized with a mixture of Rompun/Imalgen 500 and intracardiacally perfused with a solution of $4 \%$ paraformaldehyde in PBS, pH 7.2.

The brains were dissected out, post-fixed for $48 \mathrm{hr}$ in the same fixative solution at $4^{\circ} \mathrm{C}$, and then stored in PBS.

Immunohistochemistry was performed on floating or frozen sections. For floating sections, serial sagittal or coronal sections (50- $\mu \mathrm{m}$-thick) were performed with a Vibratome (Leica, Nussloch, Germany). For frozen sections, brains were immersed for $48 \mathrm{hr}$ in $30 \%$ sucrose solution at $4^{\circ} \mathrm{C}$, embedded in OCT (Tissue-Tek, Sakura, Japan) after the appropriate orientation, and frozen quickly in dry ice before cutting with a cryostat (Jung CM 3000; Leica). Coronal and sagittal sections were cut at different thickness $(6$ and $14 \mu \mathrm{m})$ and collected on Superfrost slides. Sections were processed as described previously (Calaora et al., 1996). Briefly, they were incubated overnight at $4^{\circ} \mathrm{C}$ with one of the following antibodies: anti-mCD24, rat monoclonal $\operatorname{IgG}$ (dilution 1:100, prepared in Rougon's laboratory; Rougon et al., 1991), anti-polysialic acid (PSA)neural cell adhesion molecule (NCAM), mouse monoclonal IgM (dilution 1:100, prepared in Rougon's laboratory; Rougon et al., 1986), anti-GFAP, rabbit polyclonal IgG (1:100; Sigma, St. Quentin Fallavier, France), or monoclonal mouse IgG (1:2000; Sigma) and anti-S100, rabbit polyclonal IgG (1:100; Dako, Glostrup, Denmark). Sections were then washed in PBS before incubation in the corresponding fluorescent secondary antibodies (1:50; Immunotech S.A., Marseille, France) for $1 \mathrm{hr}$ at room temperature. Sections were observed with a fluorescence microscope (Axioskop; Zeiss, Oberkochen, Germany) or a confocal laserscanning microscope (Zeiss). Controls were performed either by omitting the first antibody or by replacing the first antibody with a nonimmune serum.

BrdU injections and staining. We used three different protocols: (1) a short survival protocol to label rapidly dividing cells in the SVZ and DG. The animals were perf used $1 \mathrm{hr}$ after a single intraperitoneal injection of a sterile solution of BrdU (Sigma; $10 \mathrm{mg} / \mathrm{ml}$ in PBS, $50 \mathrm{mg} / \mathrm{kg}$ of body weight). Brains were cut in serial frontal sections with a Vibratome (50- $\mu$ m-thick). Four levels were selected as described in Figure 4, and three serial sections per level were analyzed. Comparative analyses for SVZ were performed on 9 wild-type (WT) and $10 \mathrm{mCD} 24-/-$ mice. DG was serially sectioned in frontal orientation (50- $\mu \mathrm{m}$-thick). Comparative analysis in hippocampal formation were performed in five WT and six mutant mice.

(2) A longer survival protocol to label slowly dividing cells (Johansson et al., 1999): BrdU (1 mg/ml) was given to four WT and five mutant mice in drinking water for 3 or 4 weeks followed by 1 or 2 weeks without BrdU. Animals were perfused as described before. The area of the lateral ventricle was serially sectioned with a cryostat (6- $\mu \mathrm{m}$-thick). Four levels were selected (V1 to V4, as described in Fig. $7 A$ ), and five serial sections per level were analyzed.

(3) BrdU cumulative labeling method to determine the labeling index
(LI). WT and mutant animals received intraperitoneal injections of BrdU (Sigma; $10 \mathrm{mg} / \mathrm{ml}$ in PBS, $50 \mathrm{mg} / \mathrm{kg}$ of body weight) for $1,2,4,5$, or $6 \mathrm{hr}$ (every $2 \mathrm{hr}$ ) (Nowakowski et al., 1989). For the two groups (WT and mutant), we analyzed three sections per animal, each group being composed of three animals.

In all cases, sections were treated for $30 \mathrm{~min}$ at $37^{\circ} \mathrm{C}$ with $\mathrm{HCl} 2 \mathrm{~N}$ in PBS containing $0.5 \%$ Triton $\mathrm{X}-100$, to denaturate the DNA under single strand. Then, they were rinsed in sodium tetraborate buffer $(0.1 \mathrm{M}, \mathrm{pH}$ 8.5 ) to restore neutral $\mathrm{pH}$ and processed for immunohistochemistry, as described above, using an anti-BrdU antibody (1:100; Dako). For cumulative assays we performed a double-labeling BrdU-PCNA. In this case, steps of denaturation were preceded by $70 \%$ ethanol permeabilization $\left(-20^{\circ} \mathrm{C}\right)$ necessary for PCNA staining $(1: 400$; rabbit polyclonal $\mathrm{IgG}$; PC474, Oncogene, Boston, MA) to detect its expression in all phases of the cell cycle (Dehay et al., 2001).

For statistical analysis (short and long survival protocols), all the BrdU-immunopositive cells were counted in the WT and mutant mice with a fluorescence microscope at $40 \times$ objective (Axioskop; Zeiss). Total number of cells was counted after nuclei counterstaining with Hoechst.

For BrdU cumulative labeling, to determine the $\mathrm{LI}(\mathrm{BrdU}+/ \mathrm{PCNA}+)$ we counted the BrdU+ and PCNA+ cells (Axioskop with carv optical module for confocal microscopy; Zeiss) in equivalent SVZ field of view in the WT and mutant mice.

SVZ explant culture and cell migration distance. Cultures of SVZ explants were performed as described in Wichterle et al. (1997). Briefly, mice (WT and mCD24-/-) were killed by rapid decapitation. Brains were dissected out and placed in cold HBSS medium (Invitrogen, Gaithersburg, MD). After Vibratome sectioning, the SVZ from the lateral wall of the anterior horn of the lateral ventricle was dissected out from the appropriate section and cut into pieces of $100-300 \mu \mathrm{m}$ in diameter. The explants were mixed with $70 \%$ Matrigel in HBSS medium (Becton Dickinson, Mountain View, CA) and cultured in four-well dishes. After polymerization for $10 \mathrm{~min}$, the gel was overlaid with $2 \mathrm{ml}$ of serum-free medium containing B-27 supplement (Invitrogen), in presence or absence of $70 \mathrm{U}$ of Endoneuraminidase (EndoN) prepared in our laboratory (Wang et al., 1994). Cultures were maintained in a humidified, 5\% $\mathrm{CO}_{2}, 37^{\circ} \mathrm{C}$ incubator.

After $48 \mathrm{hr}$ in culture, explants were examined using a phase-contrast microscope (Axiovert $135 \mathrm{M}$; Zeiss). Images were collected with a video camera (Cool View; Photonic Science) digitized and analyzed using image-processing software (Visiolab 2000; Biocom). Migration distance was calculated as the distance (in micrometers) between the edge of the explant and the border of the cell migration front. Twenty-four measurements were performed for each explant regularly distributed around the explant. Nine explants were analyzed per condition. The significance of the differences in cell migration under the three experimental conditions was calculated by ANOVA (WT vs WT + EndoN and $\mathrm{WT}$ vs $\mathrm{mCD} 24-/-$ mice).

Olfactory bulb volume. For OB volume estimation, brains of four WT and four mutant mice were serially cut with a Vibratome $(50-\mu \mathrm{m}$-thick). Area $A_{\mathrm{n}}$ (in square micrometers) of each section was measured with Visiolab 2000 software to calculate the volumes by $\Sigma\left(A_{1} \times A_{\mathrm{n}}\right) \times 50.10^{-3}$ (in cubic millimeters).

Terminal deoxynucleotidyl transferase-mediated biotinylated UTP nick end labeling assay for detection of apoptotic cells. To detect apoptotic cells in the RMS, we used the ApopTag Peroxidase in Situ Detection Kit (Intergen, Purchase, NY). In apoptotic nuclei, DNA is fragmentated as multimers of $\sim 180$ bp nucleosomal units. In such a method, these nucleosomal units are stained by polymerization of the free $3^{\prime} \mathrm{OH}$ termini by terminal deoxynucleotidyl transferase with modified nucleotides (digoxigenin-conjugated dUTP). They were identified with an antidigoxigenin peroxidase conjugated antibody. We used the Peroxidase substrate kit (Vector Laboratories, Burlingame, CA) as chromogenic substrates. To quantify the number of apoptotic cells in the RMS of the WT and mutant mice, we subdivided it into four regions as described in Figure $9 C$. The total number of cells was estimated on sections counterstained with solid red nuclear.

Statistical analyses. To compare between WT and mutant mice the number of BrdU + cells, the ratio BrdU $+/$ Hoechst + cells, the LI $(\mathrm{BrdU}+/ \mathrm{PCNA}+)$ and terminal deoxynucleotidyl transferase-mediated biotinylated UTP nick end labeling (TUNEL)-positive cells, we performed statistical analysis on values with the Statview Software. Data from BrdU experiments (cumulative and noncumulative methods), TUNEL labeling, and olfactory bulb volume of the two experimental 
groups (WT and mCD24-/- mice) were subjected to a comparison using the Student's $t$ test. All values were given as mean \pm SEM.

Conventional electron microscopy. Animals were deeply anesthetized with an overdose of xylazine-ketamine and successively perfused with $5 \mathrm{ml}$ of PBS, $20 \mathrm{ml}$ of $2 \%$ paraformaldehyde, and $2 \%$ glutaraldehyde in $0.1 \mathrm{M}$ sodium phosphate buffer, $\mathrm{pH} 7.4$, and $10 \mathrm{ml}$ of the same fixative without glutaraldehyde but containing sodium- $m$-periodate and lysine. Brains were transversally sectioned in $80-\mu \mathrm{m}$-thick sections with a Vibratome (Leica), and selected sections containing the RMS were post-fixed for $1 \mathrm{hr}$ in osmium tetroxide. Dehydration was performed through increasing concentrations of ethanol followed by immersion in propylene oxide, propyleneEpon solution (1:1), and finally pure Epon. After infiltration overnight in Epon, the slices were flat-embedded between plastic slides. Selected areas from the RMS were cut from the plastic wafer and ultrathin sectioned. The sections were mounted on single-hole copper grids, stained with lead citrate, and examined with a Zeiss electron microscope.

Pre-embedding immunogold electron microscopy. Animals were perfused with a mixture of $4 \%$ paraformaldehyde and $0.1 \%$ glutaraldehyde. Selected Vibratome sagittal sections $(80 \mu \mathrm{m})$ of the brains were incubated with anti-mCD24 antibody (rat IgG; dilution 1:500; prepared in Rougon's laboratory), for $24 \mathrm{hr}$ at $4^{\circ} \mathrm{C}$. Then, they were post-fixed for 2 $\mathrm{hr}$ in $4 \%$ paraformaldehyde and incubated again for $24 \mathrm{hr}$ at $4^{\circ} \mathrm{C}$ in the secondary $0.8 \mathrm{~nm}$ gold antibody (goat anti-rat IgG; Aurion, Wageningen, The Netherlands) diluted 1:30 in $0.1 \%$ fish gelatin. This secondary antibody incubation was followed by a silver enhancement reaction (10 min). The sections were then osmicated, dehydrated, and flat embedded in Epon resin. Ultrathin sections were performed on selected areas and visualized with a Zeiss electron microscope.

\section{RESULTS}

\section{mCD24 deletion does not perturb chain-like migration}

In sagittal Nissl-stained sections of adult WT mice, the RMS appeared as a long, continuous irregular shaped row of tightly packed cells linking the anterior horn of the lateral ventricle to the ipsilateral OB (Fig. $1 A$ ). In the mCD24-/- mutant mice, we did not observe any modification in the size of their brain or their ventricles (Fig. $1 B$ ). The RMS had the same location and shape than in the WT, and no sign of enlargement was detectable.

In the $\mathrm{WT}, \mathrm{mCD} 24$ was expressed along this entire migratory pathway from the ventricular border of the lateral ventricle $(\mathrm{V})$ to the OB (Fig. $1 C$ ), and it was coexpressed with PSA-NCAM on most of the migratory neuronal precursor cells (Fig. 1D, see enlargement).

We previously showed at the optical level that mCD24 was expressed on cells in the SVZ where neurogenesis persists in adult mice and in the ependymal layer (Calaora et al., 1996). Here, we localized more precisely the $\mathrm{mCD} 24$ expression in the zones bordering the lateral ventricle. Confocal laser microscopy analysis, in 6- $\mu \mathrm{m}$-thick sections, indicated that mCD24 immunoreactivity was located on the tuft of cilia of all ependymal cells (Fig. 1E, arrow) and on the membrane of cells located in the SVZ (Fig. 1E, double arrow). Moreover, we observed that mCD24 was also expressed on all the ciliated cells lining the other ventricles (IIIth, IVth and central canal of the spinal cord, data not shown). These data indicated that mCD24 is a general marker of ependymal cells. Its location was confirmed at the electron microscopic (EM) level. mCD24 was specifically expressed on the apical membrane of ependymal cells and their associated microvilli and cilia (Fig. 1F, arrow) (insert is a higher magnification of cilia labeled with mCD24). In addition, cells strongly labeled with mCD24 were found in the SVZ (Fig. $1 F$, asterisk). Their morphology was very similar to that of the migrating neuronal precursors cells (type A cells), described by Doetsch et al. (1997).

To study the organization of migrating neuroblasts in the mCD24-/- mice, we used PSA-NCAM, a widely used marker of neuroblasts in the pathway (Chazal et al., 2000). In WT mice, the chain-like migrating neuroblasts PSA-NCAM+ (Fig. $2 A$, arrow), were ensheated by processes of astrocytes rostrocaudally oriented as already described (Jankovski and Sotelo, 1996; Lois et al., 1996). These neuroblast-glial arrangements were conserved in mutant mice (Fig. 2B, arrow). This was confirmed at the ultrastructural level. Frontal sections through the WT and mutant RMS showed the same degree of cell arrangement: groups of neuronal precursors surrounded by astrocytes filled up the whole space of the RMS (Fig. 2, compare $C, D$ ). At higher magnification, we can clearly see the darkly stained electron dense nuclei of neuronal precursors (type A cells) regrouped around astrocytes (type B cells) identified by their lighter-stained cytoplasm and glycogen granules in their cytoplasm (Fig. $2 E$ ). In the mutant no obvious modification of this organization was visible, and close contacts between cells were preserved (Fig. $2 F$ ).

To confirm that mCD24 was not implicated in the migration of neuroblasts in this zone of neurogenesis, we used an in vitro assay in which we compared the migration of cells from WT and mCD24-/- SVZ explants (Fig. 3). After 48 hr in culture, a network surrounding the explants was visible in the different conditions (Fig. 3A,C,E). We treated explants with EndoN as a positive control. Removal of PSA by EndoN significantly reduced the distance of cell migration (Fig. 3C) (133.09 $\pm 5.00 \mu \mathrm{m}$ for WT and $66.10 \pm 2.47 \mu \mathrm{m}$ for WT + EndoN), as already described by Chazal et al. (2000). We compared cell migration between WT (Fig. 3A) and mCD24-/- mice (Fig. 3E). Statistical analysis did not reveal any significant difference $(133.09 \pm 5.00 \mu \mathrm{m}$ for WT and $145.87 \pm 5.79 \mu \mathrm{m}$ for $\mathrm{mCD} 24-/-$ mice) (Fig. $3 G, H$ ). SVZ cells migrating outside the explant were organized in the same chain-like arrangement in both WT (Fig. 3B) and mCD24-/(Fig. $3 F$ ) in comparison with explant cultured with EndoN, where chains presented a lower degree of compaction (Fig. 3D). These data clearly indicate that mCD24 is not directly implicated in the migration of the neuronal precursors.

\section{Increased number of proliferating cells in the mCD24 -/- mice}

We previously showed that mCD24 is expressed on ependymal cells and on BrdU+ neuroblasts (Chazal et al., 2000). To confirm the expression of mCD24 on proliferating cells we performed double labeling with mCD24 and PCNA. PCNA is a non-histone protein associated with the DNA polymerase delta and expressed in all phases of the cell cycle (Sasaki et al., 1993). We observed double mCD24+/PCNA+-labeled cells in the SVZ (Fig. 5A), suggesting its implication in cell proliferation. We asked whether the inactivation of the $m C D 24$ gene could affect the number of proliferating cells. SVZ contains at least two populations of cells discriminated by their rate of proliferation: one defined as the constitutively rapidly proliferating neuroblasts and the other characterized as relatively quiescent cells described as stem cells (Morshead and van der Kooy, 1992; Morshead et al., 1994; Chiasson et al., 1999; Doetsch et al., 1999; Johansson et al., 1999). Based on different periods of BrdU incorporation to discriminate between rapid and slow dividing cells, we analyzed and compared the effect of the $m C D 24$ mutation.

\section{Increased number of rapidly proliferating cells in SVZ of mutant mice}

To study exclusively the population of rapidly proliferating cells, we analyzed the animals $1 \mathrm{hr}$ after an intraperitoneal injection of BrdU. While en route to the OB, a vast number of cells are dividing from the SVZ to the OB (Menezes et al., 1995). Accordingly, we selected four rostrocaudal levels along the RMS, as 

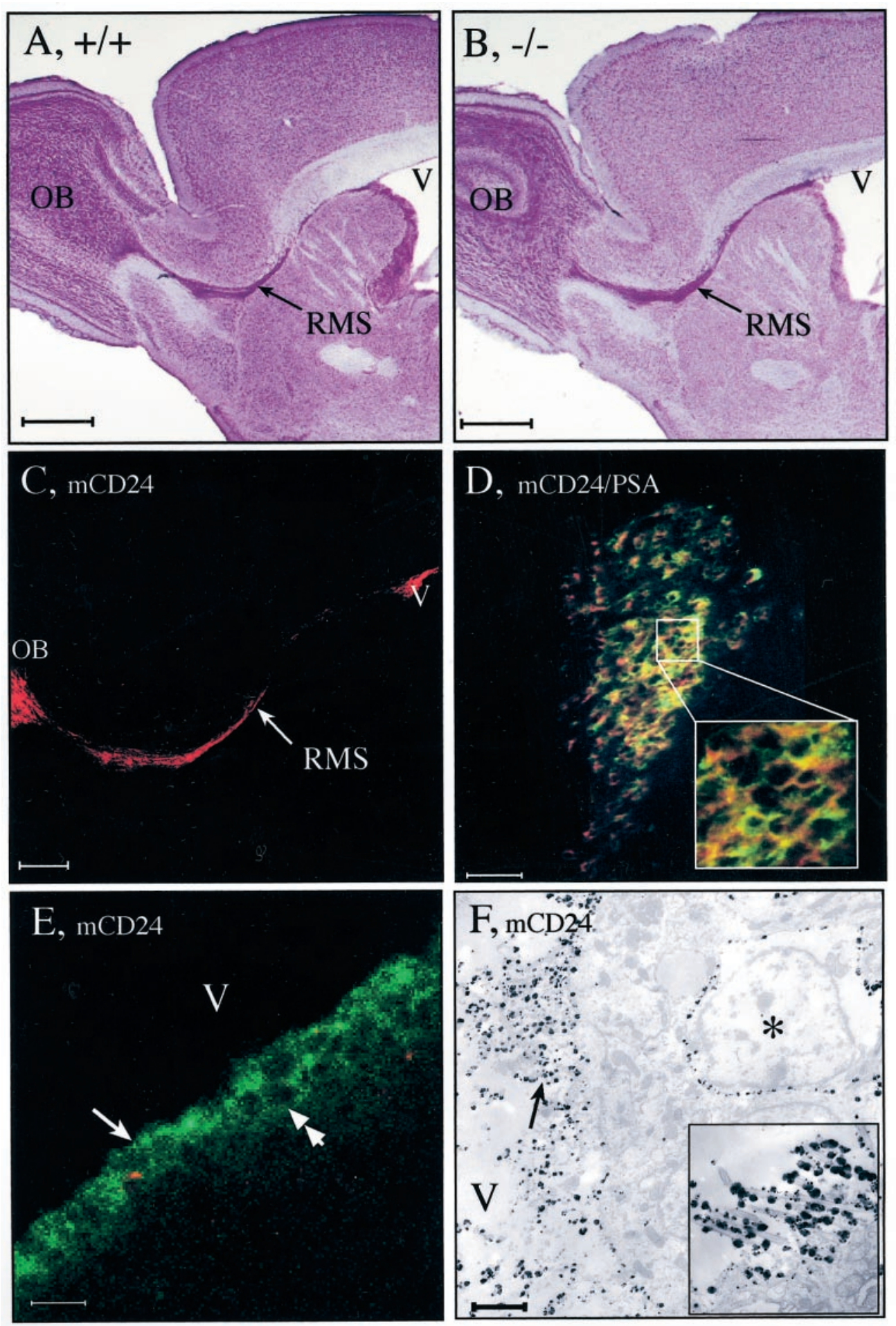

Figure 1. Localization of the RMS in the adult WT $(A,+/+)$ and $\mathrm{mCD} 24-/-$ mice $(B,-/-)$. In sagittal sections from a Nissl stain preparation, the RMS of the WT appears as a continuous pathway connecting the anterior horn of the lateral ventricle $(V)$ to the center of the olfactory bulb $(O B)$. In the mCD24-/-, the pathway has the same location and shape $(B)$. There is no distortion or increase in size of the ventricle. Expression of $\mathrm{mCD} 24$ in the WT RMS $(C, D)$; $\mathrm{mCD} 24$ (red) is expressed on migrating cells all along the pathway (arrow) from the ventricle $(V)$ to the olfactory bulb $(O B)$ and is primarily coexpressed with PSA-NCAM $(D)$ (green). This can be clearly seen on the square in $D$, representing an enlargement of the core of the RMS. Expression of mCD24 is on ventricular zones $(E, F)$. Confocal microscopy $(E)$ reveals that $\mathrm{mCD} 24$ labeling is expressed on the membrane of ciliated ependymal cells lining the lateral ventricle (arrow). In addition, mCD24 is also expressed on the membrane of precursor cells present in the SVZ (double arrow). At the EM level $(F)$, silver-enhanced gold particles reveal the mCD24 labeling on the membrane of microvilli and cilia of these cells (arrow) (insert: enlargement of cilia labeled with gold particles). In the SVZ, we can localize mCD24 on the membrane of some type A cells (asterisk). Scale bars: $A, B, 1 \mathrm{~mm} ; C, 500 \mu \mathrm{m} ; D, E, 50 \mu \mathrm{m}$; $F, 1 \mu \mathrm{m}$. described in Figure $4 A$, from the emergence of the stream (Fig. $4 B 1$ ) to the core of the OB (Fig. 4B4). In the WT as well as in the mCD24-/- mice, BrdU+ cells were present along the entire pathway from the SVZ to the OB (Fig. $5 B$ ). In these frontal levels we counted the number of BrdU+ cells in the RMS of WT and mutant mice. The absolute number of BrdU+ cells followed a rostrocaudal gradient. Although the SVZ contained the highest number of BrdU+ cells (Fig. 5B, level 1), we found a sharp decrease of labeled cells along the pathway toward the OB. However, some BrdU+ cells were still visible in the OB (Fig. $5 B$, level 4). In mutant mice, the total number of BrdU+ cells followed this general distribution along the pathway (Fig. 5B, levels 1-4). Interestingly, in the mutant SVZ, the total number of BrdU+ cells was significantly higher compared with the WT $(525.9 \pm 33.6$ for WT mice and $851.5 \pm 52.8$ for mutant mice; $p<$ 0.001 ) (Fig. $5 B$, level 1, compare $a, b$ ). No significant difference in the total number of BrdU+ cells was observed in the three other levels studied (levels 2-4).

Besides, mCD24 is also expressed on proliferating cells in the DG $(\mathrm{mCD} 24+/ \mathrm{PCNA}+)($ Fig. $5 A)$, the other zone of secondary 

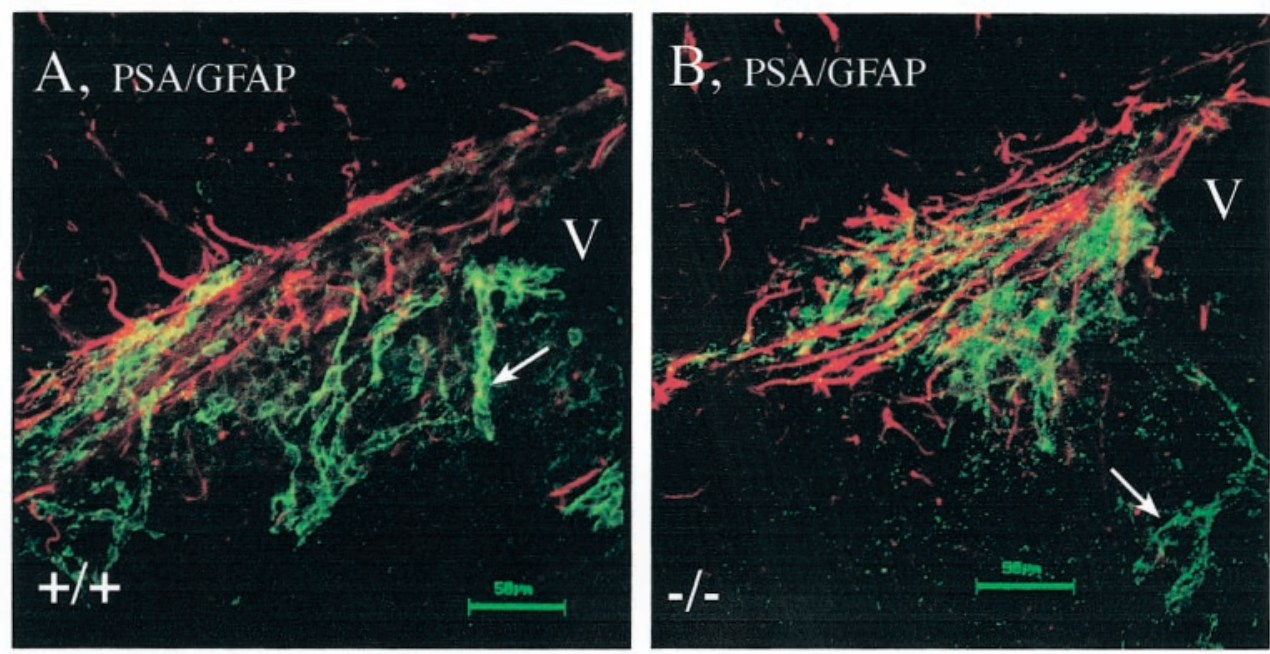

Figure 2. Neuroblast-astrocyte organization at the optical and EM levels is conserved in mCD24-/- mice. Double immunofluorescence for PSA-NCAM and GFAP in the RMS of the WT and $\mathrm{mCD} 24-/-$ mice $(A, B)$. Confocal laser imaging revealed in the WT $(A,+/+)$ and mutant $(B,-/-)$ mice the same arrangement between neuroblasts and glial cells. In both groups, the expression of PSA-NCAM clearly shows chain-like arrangement of neuronal precursors (arrows) migrating inside tangential glial structures. $C$, At the EM level, in frontal section, the RMS appears as a highly organized structure containing groups of neuronal precursors $(n)$ surrounded by astrocytes $(a)$. $D$, The mutant RMS showed the same organization. At higher magnification $(E+/+, F-/-)$, there is no sign of disorganization with neuroblasts $(N)$ still grouped together and ensheated by astrocytes $(A)$. v, Vessels, noa, nucleus olfactorius anterior. Scale bars: $A, B, 50 \mu \mathrm{m} ; C, D, 20$ $\mu \mathrm{m} ; E, F, 3 \mu \mathrm{m}$.
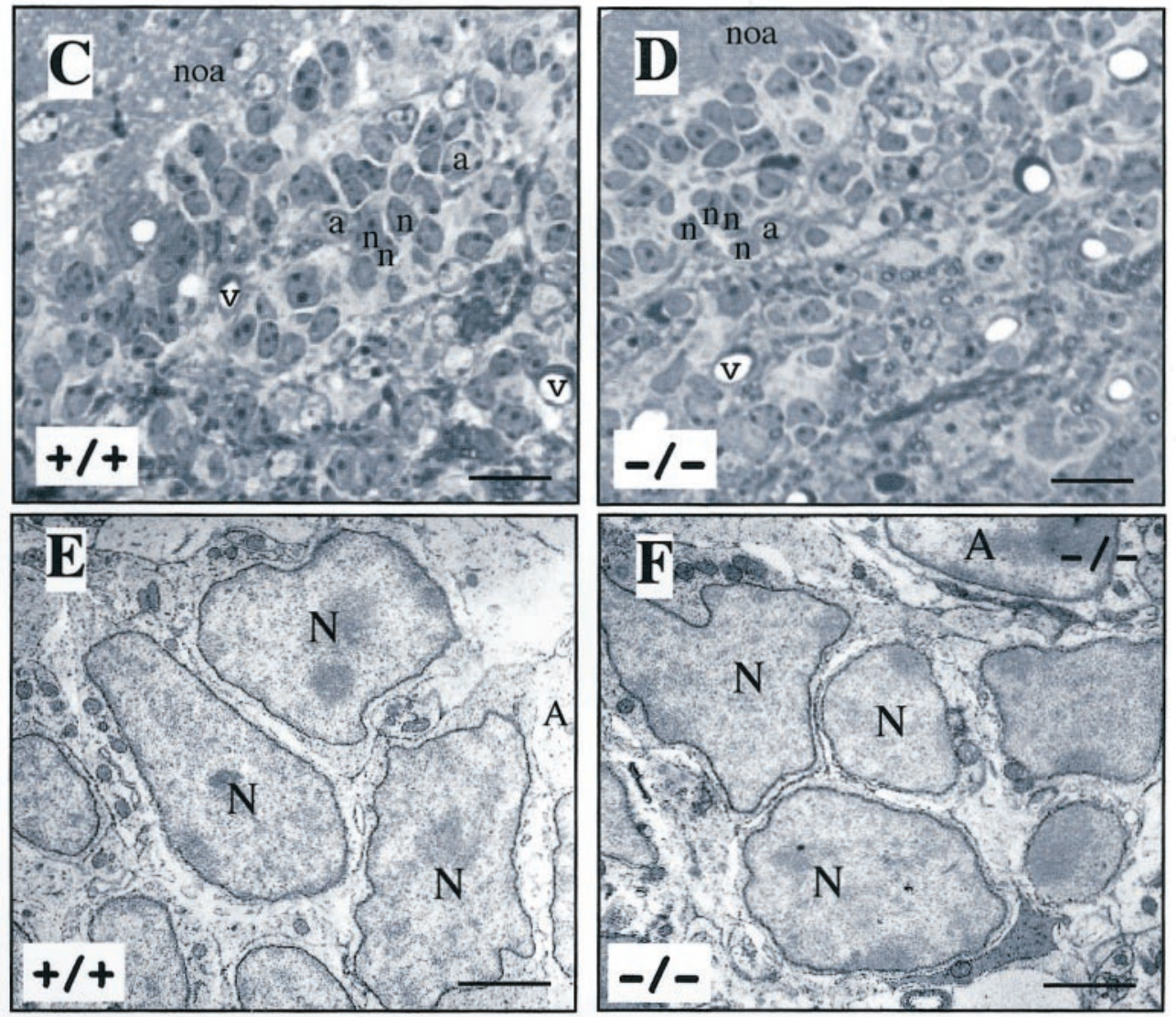

neurogenesis in the adult CNS. Newly generated granule cells were located in the subgranular zone of the DG in both WT and mutant mice (Fig. 5Ca,b). In this zone, we found a statistically significant increase in the total number of BrdU+ cells in mutant mice (Fig. $5 C$ ). As a consequence, $m C D 24$ deletion also results in an increase of rapid cell proliferation in this second zone of neurogenesis.

To study total cell cycle length of rapid proliferating cells in both WT and mCD24-/- mice, we performed BrdU cumulative labeling. Cells in S-phase at the time of the pulse were positively stained for BrdU. Proliferating cells were identified by means of PCNA labeling, assuming that its expression is not modified by the mutation. We used the BrdU cumulative labeling method to measure the Tc by determining LI values in the population of cycling cells and not in the entire population of cells as described by Dehay et al. (2001). The statistical analysis of LI revealed that total cell cycle length differed between WT and mutant because linear regressions gave two different slopes. As for example, this increase of $\mathrm{LI}$ in the $\mathrm{mCD} 24-/-$ mice (increase in the number of double-labeled cells BrdU+/PCNA+) is clearly observed at $6 \mathrm{hr}$ of cumulative injections of BrdU (Fig. $6 B a, B b$ ). In such a method, Tc can be estimated by projection on $x$-axis with the corresponding extrapolated $100 \%$ LI. We found an estimated Tc value of $\approx 10 \mathrm{hr}$ in $\mathrm{mCD} 24-/-$ mice $(\mathrm{Tc} \approx 18 \mathrm{hr}$ for WT mice) near the 18.6 hr determined by Thomaidou et al. (1997), demonstrating that inactivation of $m C D 24$ leads to a reduction of Tc. 

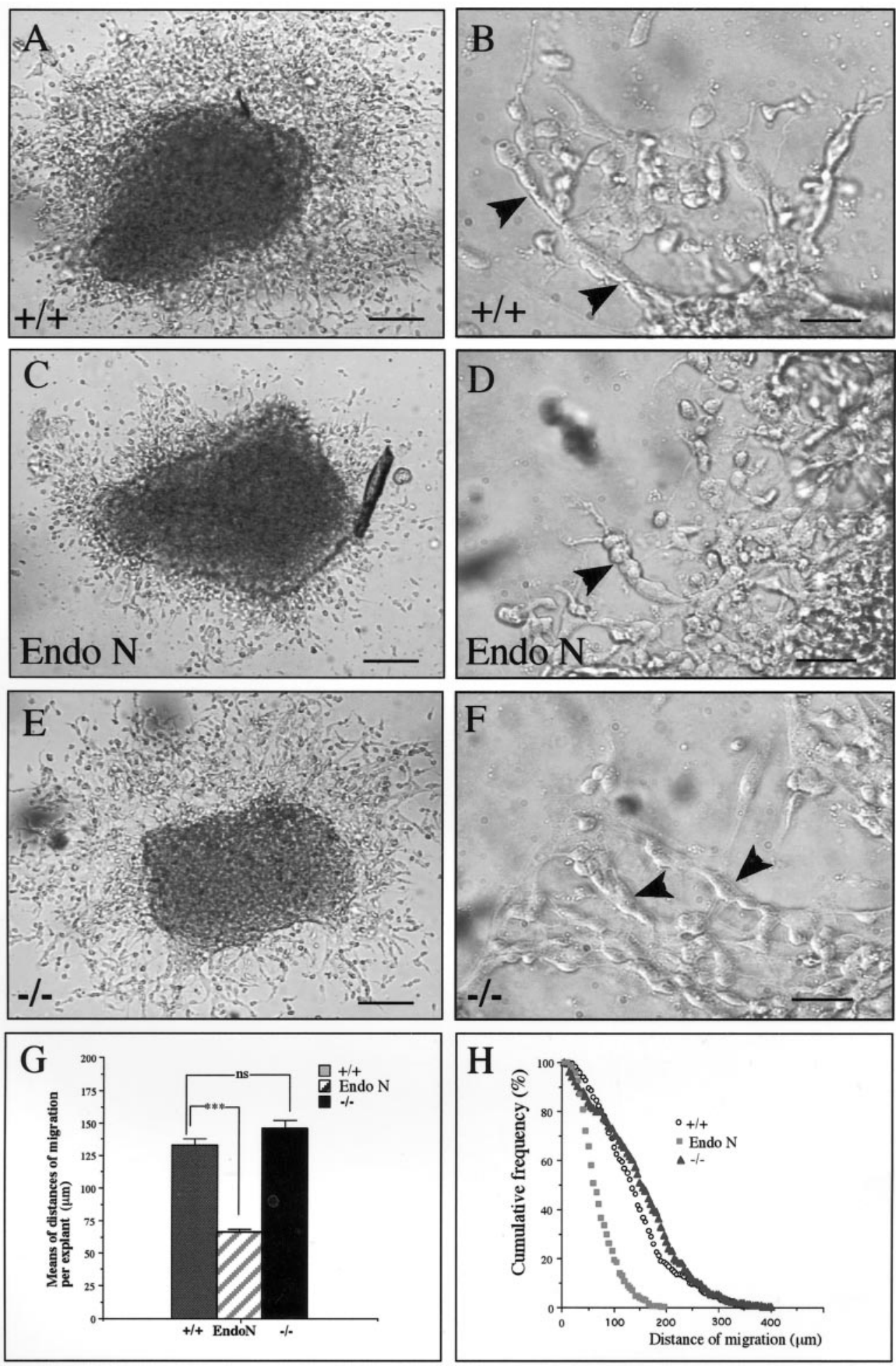

Figure 3. Comparison of the cell migration of WT and mCD24 -/- SVZ explants cultured in Matrigel. Explants were cultured from the SVZ of WT $(A)$ or mCD24 $-/-$ mice $(E)$. Explants from WT were also cultured in presence of Endoneuraminidase $\mathrm{N}$ (Endo $N$ ) as a positive control $(C)$ (Chazal et al., 2000). Cells migrate outside the explant as a regular network in WT $(A)$. At higher magnification we can see the migrating cells organized in chains ( $B$, arrowheads). In presence of EndoN (positive control), we clearly observed a reduction in size of the network $(C)$ with a decrease in the length of the chains ( $D$, arrowhead). In the explant from the mCD24-/- SVZ $(E)$, the network of cells outside the explant is similar to the WT and the cells are still organized in chains (see higher magnification in $F$, arrowheads). The results of the means of migration per explant are summarized in the diagram in $G$, demonstrating no difference in the distance of migration between WT and mCD24-/- explants. $H$, Cumulative frequency distribution plot of the distance of cell migration following the different types of explant. For the WT and mCD24-/- explants, the slopes of the respective curve are similar, indicating the same distance of migration for both groups $(* * *<0.001)$. Scale bars: $A, C$, $E, 100 \mu \mathrm{m} ; B, D, F, 20 \mu \mathrm{m}$.
Increased number of slowly proliferating cells in the SVZ of mutant mice

It is known that slowly proliferating cells are present in the SVZ of the lateral ventricle (Doetsch et al., 1999; Johansson et al., 1999). We examined whether this population was also affected by the inactivation of $m C D 24$.

To label only cells having a slow proliferating rate, we used the protocol described by Johansson et al. (1999) where the animals received BrdU continuously over a 3 or 4 week period followed by a 1 or 2 week chase period without BrdU. With these periods of chase, all the rapidly dividing and migrating cells had either migrated toward the $\mathrm{OB}$ or diluted the BrdU in successive rounds of division. Thus, only slowly proliferating cells retained the marker over time. It has been demonstrated by Doetsch et al. (1997) that the subventricular germinal zone has a heterogeneous cellular composition following the rostrocaudal orientation. For this reason, we subdivided the lateral ventricle into four different frontal levels (Fig. $7 A$, levels V1 to V4) and analyzed the number 


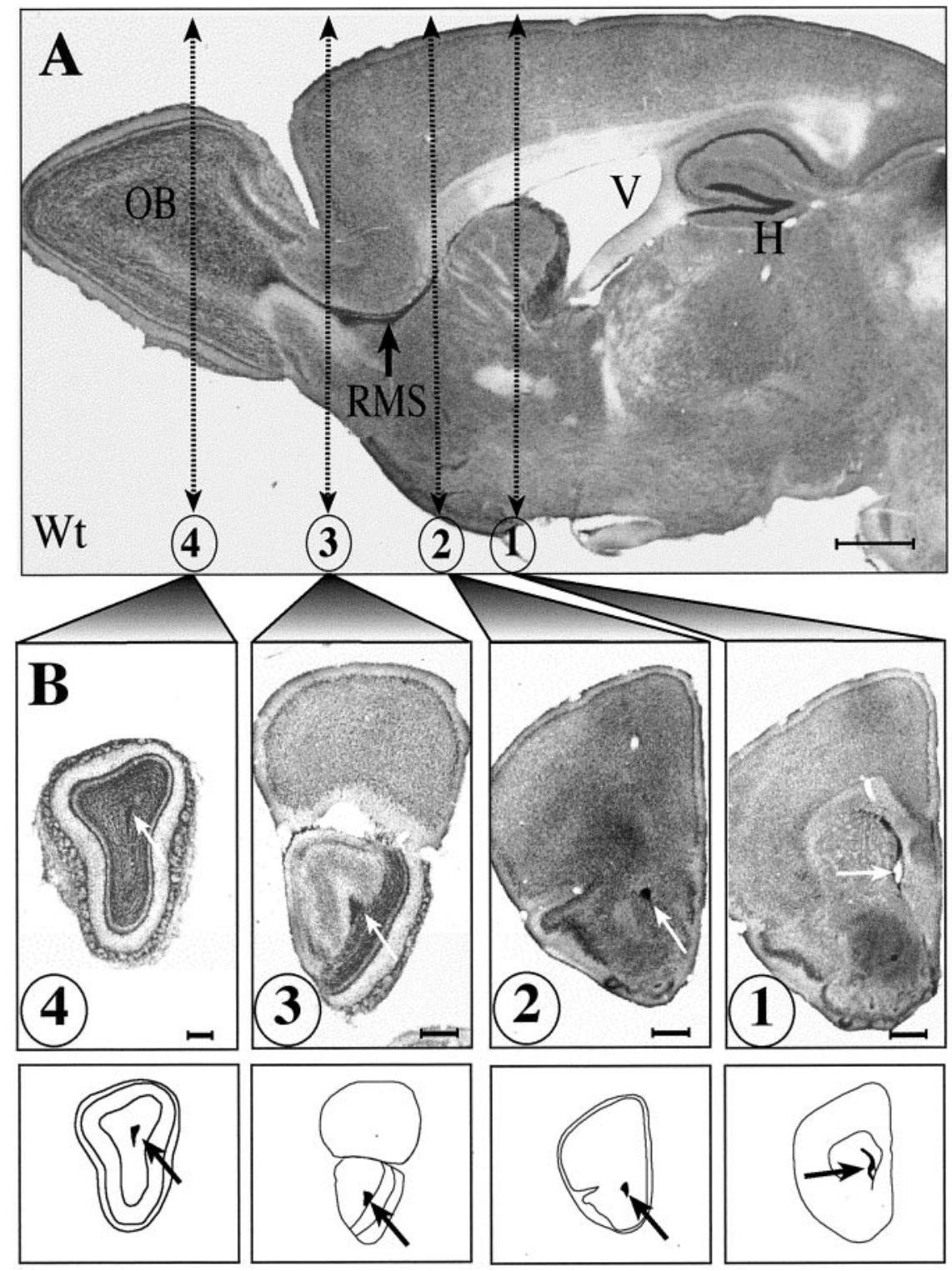

Figure 4. Light micrographs of sagittal and frontal sections from Nissl stain preparation illustrating the position of the RMS and hippocampal formation $(H)$. The RMS is clearly identifiable in sagittal $(A)$ but also in frontal sections $(B$, arrows). The four frontal sections illustrated and schematized below were selected for statistical analysis. Scale bars: $A, B, 500 \mu \mathrm{m}$.

of BrdU+ cells in WT and mutant mice. At first sight, more labeled cells were visible in the mutant mice (Fig. $7 B$, compare the number of BrdU + cells in the WT and mCD24-/- mice). At all levels studied (V1-V4), the total number of BrdU+ cells was statistically higher in mutant mice (Fig. $7 C$ ).

We showed that mCD24 is expressed on ependymal cells. Johansson et al. (1999) demonstrated that in this ependymal layer some cells can divide slowly. To search for an effect of the mutation on the proliferation of these cells, we used the cytoplasmic S100 protein as a marker of ventricular cells (Didier et al., 1986; Chiasson et al., 1999). We observed mCD24+/S100+ double-labeled cells (Fig. $8 A$ ) (see enlargement in Fig. 8B: cells having $\mathrm{mCD} 24+$ cilia have also $\mathrm{S} 100+$ cytoplasm). This demonstrated that S100, like mCD24, is a good marker for ependymal cells. Slowly dividing ependymal cells were identified using BrdUS100 double labeling. In WT mice, we observed that most of the slowly proliferating cells was located underneath the S100positive cell layer lining the ventricle (Fig. $8 C$ ). In very few cases, we found some double-labeled cells $(\mathrm{BrdU}+/ \mathrm{S} 100+$ cells $)$ in the ependymal layer of WT mice (Fig. $8 C$, insert). In mCD24-/- mice, the two populations of proliferating cells $(\mathrm{BrdU}+/ \mathrm{S} 100+$ and BrdU+/S100-) were increased (Fig. $8 D$ ). When, in a few cases, the ependymal layer was mechanically detached during the process of tissue preparation, this increase of dividing cells was observed in the two distinct zones of the mutant mice (Fig. 8D, insert). However, most of the slowly dividing cells were present in the SVZ. We quantified slowly dividing cells in the ependymal layer and the SVZ (Fig. 8E). Comparisons between the WT and the mutant mice showed for both populations (ependymal layer and SVZ) a statistically significant increase of the ratio BrdU+/ Hoechst + in all ventricular levels selected (Fig. $8 E$ ). The highest increases were observed in the more rostral level (level V1) known to be the most neurogenic (Luskin, 1993).

Taken together, these results suggested an action of mCD24 on rapid and slow neural cell proliferation in the adult SVZ.

\section{Increased programmed cell death in the mutant SVZ}

Rapidly dividing cells in the SVZ are known to renew mainly the cells in the granular and periglomerular layers of the OB. Because the proliferation of the precursors of these interneurons was 

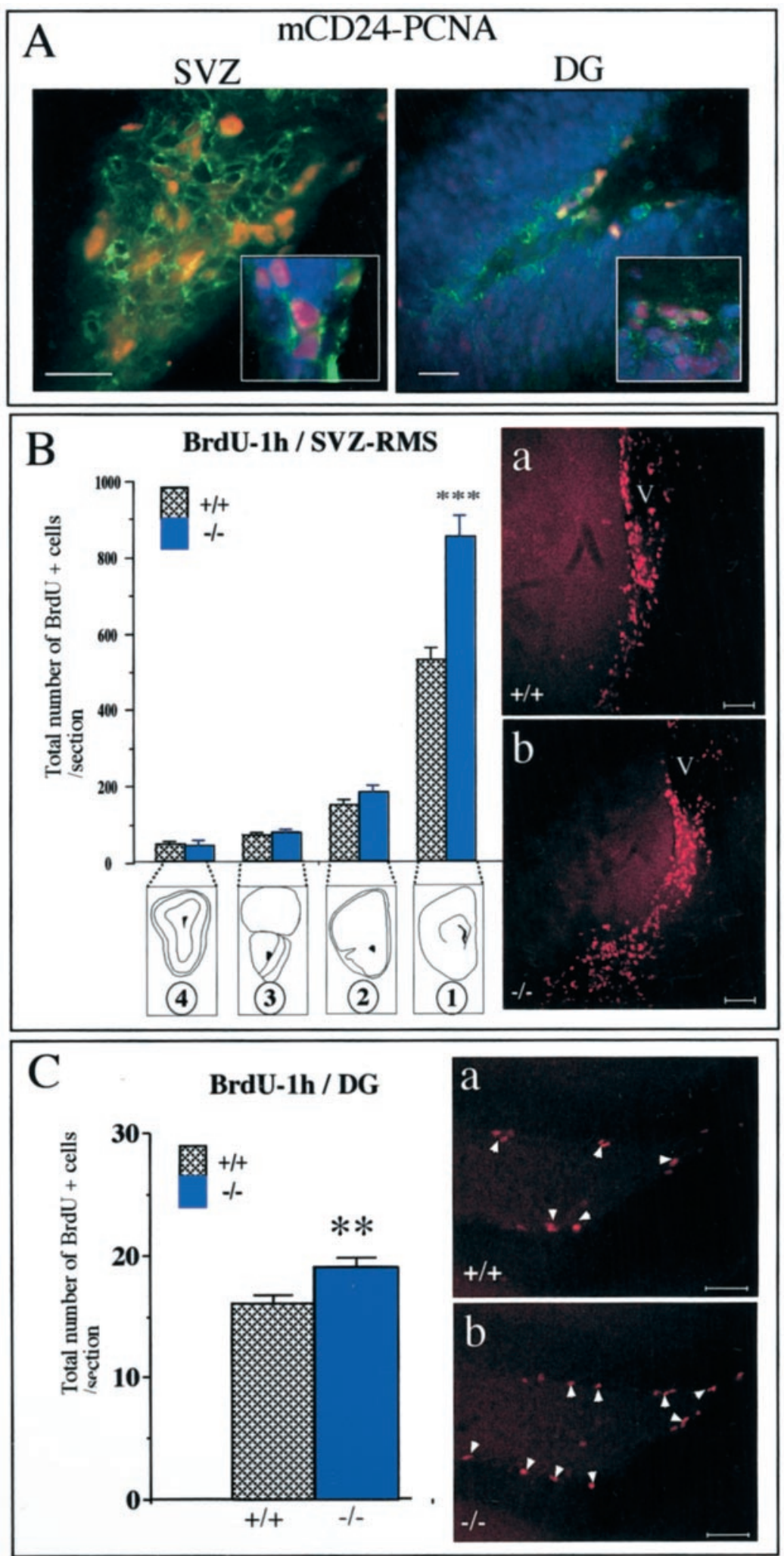

Figure 5. Increased number of BrdU+ cells in the mutant SVZ and DG. $A$, In the SVZ and DG, mCD24 (green) was present on proliferating cells labeled with the PCNA marker (red). Cells were counterstained with the nuclear marker Hoechst (blue). B, In the WT and mCD24-/- mice, BrdU+ cells were present all along the RMS. We quantified the number of these cells in the four frontal levels selected (B1-4). An increased number of BrdU+ cells was detected only at level $1(S V Z)$ in the mCD24-/- mice. No significant difference in the number of BrdU+ cells between WT and mutant was observed in the other levels $(* * * p<0.001 \mathrm{com}-$ pared with WT). Example of this increased number of $\mathrm{BrdU}+$ cells in the SVZ in the WT $(a)$ and $\mathrm{mCD} 24-/-(b)$ mice. $C$, In the WT and mCD24-/- hippocampal formation, $\mathrm{BrdU}+$ cells were visible only in the subgranular zone of the DG. Labeled cells spanning the entire extent of the DG were counted. A significant increase of BrdU+ cells, expressed as a total number of BrdU+ cells per section, were detected in the DG of the mutant mice $\left({ }^{* *} p<0.01\right.$ compared with $\left.\mathrm{WT}\right)$. Scale bars: $A, 30 \mu \mathrm{m} ; B a, b-C a, b, 50 \mu \mathrm{m}$. increased in the mCD24 mutant, one might have expected to observe an increase in the size of the OB. We evaluated the volume of the OB in WT and mutant mice. No significant difference in the volume was detectable between WT and mutant OB $\left(4.44 \pm 0.31 \mathrm{~mm}^{3}\right.$ for the WT and $4.69 \pm 0.39 \mathrm{~mm}^{3}$ for the mutant mice), ruling out the possibility of a global outgrowth of the OB. Alternatively, a counterbalance in the number of cells reaching the $\mathrm{OB}$ could occur by regulation of migration or programmed cell death (PCD). The fact that we did not observe any perturbation in the cell migration in $\mathrm{mCD} 24$-deficient mice (Fig. 2), contrary to NCAM-deficient mice (Chazal et al., 2000), led us to suggest a regulation in PCD. TUNEL labeling in the WT and 
Figure 6. Comparison of the cell-cycle length in the $\mathrm{WT}$ and $\mathrm{mCD} 24-/-$ mice. $A$, Graphic representation of the LI of the population of cycling cells (i.e., the percentage of PCNA+ cells that have incorporated $\mathrm{BrdU}$ ) in the WT and $\mathrm{mCD} 24-/-$ mice. Values are \pm SEM. ANOVA statistical analysis showed significant different slopes of linear regression for both groups, indicating different cell-cycle length. $B$, Example of an increased number of double-labeled cells BrdU+ (green)/PCNA + (red) in the mutant SVZ at $6 \mathrm{hr}$ of cumulative BrdU, reflecting an increased LI. Scale bars: $B a, b, 25 \mu \mathrm{m}$.
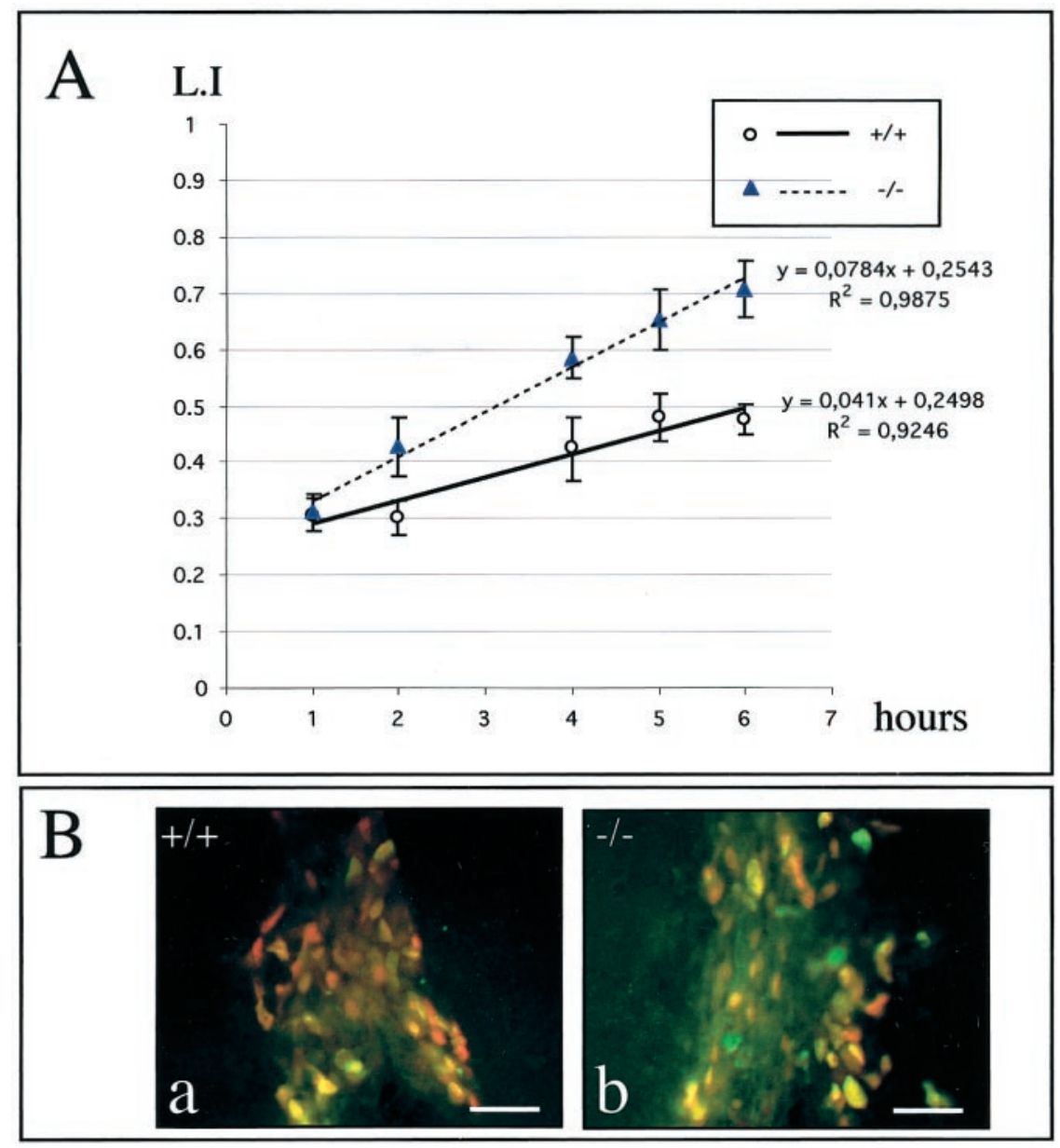

mutant mice revealed characteristic dark round apoptotic nuclei distributed from the SVZ (Fig. 9A1,2, arrows) and along the RMS (Fig. 9A3-3'). We counted these cells in the pathway in sagittal sections subdivided into four different zones (Fig. 9C). In both WT and mutant mice, apoptotic cells were more numerous in the SVZ (Fig. 9B, level I) and OB (Fig. 9B, level IV). Interestingly, the comparison of the number of apoptotic cells between WT and mutant mice showed a twofold increase in cell death specifically in the SVZ of the mCD24-/- mice (Fig. 9B, level I). There was no significant difference in the other levels. This was confirmed by the comparison in the absolute number and percentage of apoptotic cells per zone (Fig. 9D). Such differences in PCD in the SVZ between the WT and mutant animals could explain why no difference was observed in the size of the mutant OB.

\section{DISCUSSION}

mCD24 is a small highly glycosylated GPI-anchored protein. Here, we show that in adult mice, inactivation of the $m C D 24$ gene did not alter neuronal cell migration but results, in an increase of: (1) rapid proliferating neuronal precursors present in the SVZ (with a global reduction of their cell cycle length) and in the DG, and (2) slow proliferating cells in the SVZ and in the ependymal layer. These results point to a role for $\mathrm{mCD} 24$ in the regulation of cell proliferation. Finally, we found that an increased apoptosis in the mutant SVZ can compensate overproliferation and maintain a normal size of the OB.

\section{mCD24 is not involved in cell migration but regulates cell proliferation}

It is now well established that in the adult mammalian brain proliferative populations reside in two discrete regions: the SVZ of the lateral ventricle and the DG of the hippocampal formation (Altman, 1969; Lois and Alvarez-Buylla, 1993; Luskin, 1993). In the SVZ, two distinct populations of cells can be distinguished on the basis of their proliferation rate: the constitutively proliferating cells with a short cell cycle (several hours) (Morshead and van der Kooy, 1992; Thomaidou et al., 1997) and cells with a longer cell cycle (15 d or more) described as a stem cell population (Morshead et al., 1994, 1998; Doetsch et al., 1999; Johansson et al., 1999).

mCD24 is primarily expressed on proliferating precursors (PCNA + cells) that are mainly migrating neuroblasts (type A cells) and on ependymal cells. We used complementary different in vivo and in vitro approaches to appreciate its possible implication in neuronal cell migration. In all our observations, migration in mutant was identical to the WT because neuroblasts are still organized as chain-like migrating cells that migrate in the same manner out of an in vitro explant.

We showed that the $m C D 24$ deletion affects the size of both rapid (SVZ and DG) and slow (SVZ) proliferating cell populations. The effect of the deletion is particularly marked in the anterior part of the SVZ known to produce preferentially neuroblasts (Luskin, 1993; Doetsch et al., 1997). These results are compatible with the predominant mCD24 expression on neuronal 

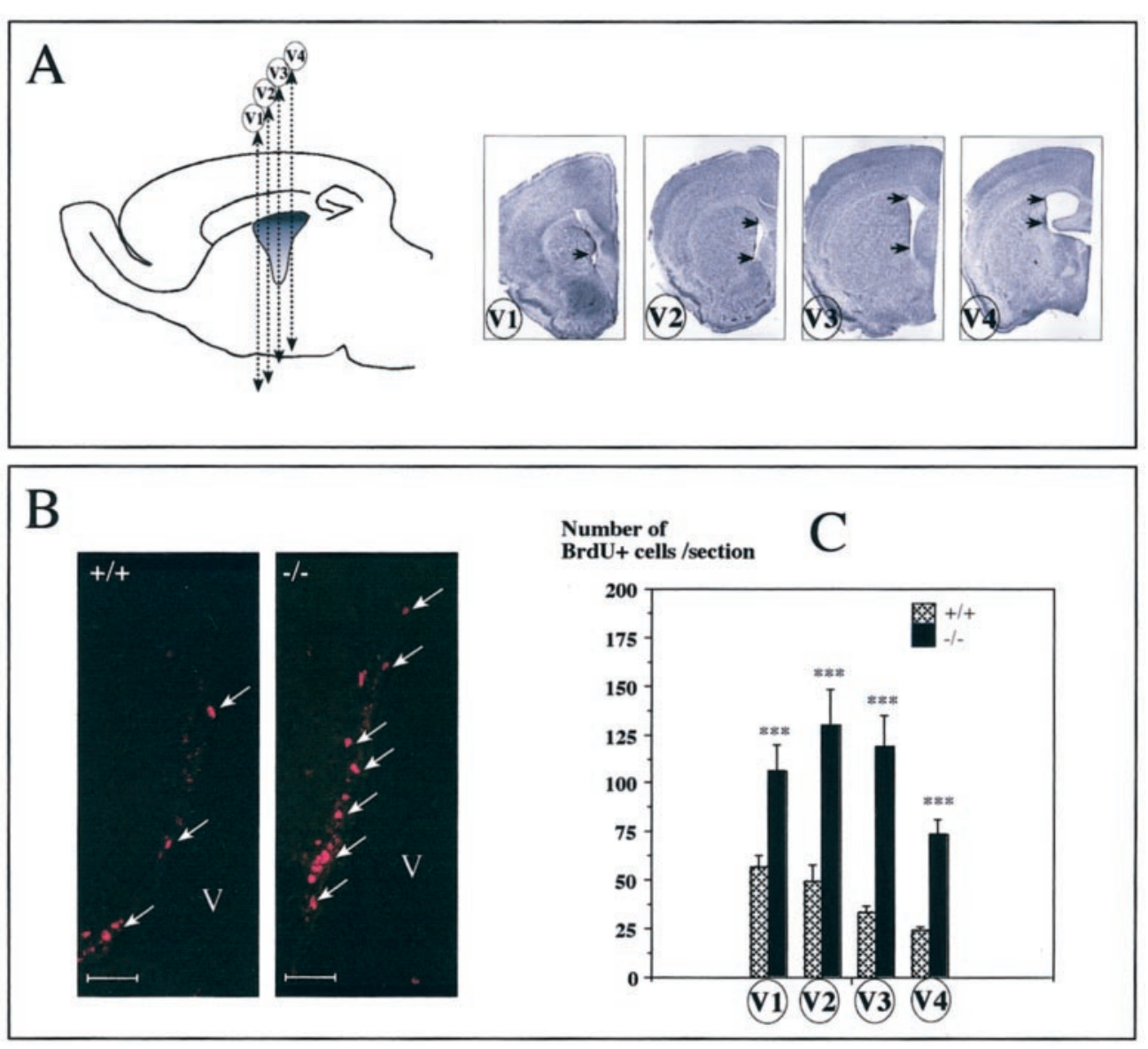

Figure 7. Increased number of BrdU+ cells in the SVZ of the mCD24-/- mice after a pulse-chase protocol. $A$, The lateral ventricle was cut in frontal serial sections as shown in the diagram. For the quantification, we selected four frontal levels (V1-V4) and counted the BrdU+ cells in the areas delineated by arrows. $B$, Examples of BrdU+ cells (arrows) in the SVZ of the WT and mCD24-/- mice. We can clearly notice an increase in BrdU+ cells in the mutant mice. $C$, Quantification of the proliferation expressed as an absolute number of BrdU+ cells per level revealed a significant increase in the number of BrdU + cells in the mutant mice in the four levels selected $(\mathrm{V} 1-\mathrm{V} 4)(* * * p<0.001$ compared with WT). Scale bars, $50 \mu \mathrm{m}$. committed cells. Besides, estimations of LI revealed a reduction of Tc in rapidly proliferating neuronal precursors of the SVZ. In mammalian cell types, S-phase length is generally constant, and variation of Tc reflects in fact variation of the G1 phase length (Pardee, 1989). It seems reasonable to propose that suppression of mCD24 expression primarily induces a deregulation of cell proliferation in a cell autonomous manner. Interestingly, reported mCD24 functional interaction involves Lyn kinase (Stefanova et al., 1991; Zarn et al., 1996), whose activation could block the G1/S transition (Wang et al., 2000). This tyrosine kinase is mostly expressed in tissues of lymphoid origin but is also found in neurons of the DG (Chen et al., 1996). As a consequence, the lack of mCD24 could facilitate $\mathrm{G} 1 / \mathrm{S}$ transition, generating an increased proliferation.

Slowly proliferating neural stem cells have been identified both in SVZ and in the ependymal layer (Morshead et al., 1994; Doetsch et al., 1999; Johansson et al., 1999). We showed in the mutant mice a significant increase in the total number of slow proliferating cells located in these areas. Altogether, mCD24 appears to be a molecule that negatively controls cell proliferation at different stages of the neural fate. A possibility is that mCD24 function is linked to the maintenance of cells in a quiescent state. This for example, fits with our observations that its deletion results in a proliferation of ependymal cells which are mainly quiescent. Our data however, do not allow to decide whether these cells represent a neural stem cell population (Johansson et al., 1999).

\section{mCD24 interactions in the regulation of cell proliferation events}

mCD24 is likely a bifunctional molecule that can undergo several interactions and can act as a ligand and a co-receptor. It has been shown to be involved in cell adhesion and signaling. Adhesion molecules have been reported to control neural cell proliferation in adult rodents. For example, the NCAM acts as an inhibitory regulator of neural progenitor cell cycle (Amoureux et al., 2000), and alteration of Eph/ephrin signaling creates bulbous hyperplasia in SVZ (Conover et al., 2000). Cross-linking of mCD24 by monoclonal antibodies induces a rapid increase in intracellular $\mathrm{Ca}^{2+}$ and inhibition of aggregation B cells (Fischer et al., 1990; Kadmon et al., 1992, 1995).

In the SVZ, several trophic factors have been described to be regulators of cell proliferation such as epidermal growth factor, TGF- $\alpha$, FGF2, IGF, PDGF, and BDNF (Craig et al., 1996; Kuhn et al., 1997; Tropepe et al., 1997; Zigova et al., 1998). These regulatory factors exert their action through cell surface receptors expressed by neuronal precursors. One cannot exclude cis regulatory interactions between $\mathrm{mCD} 24$ and receptor(s) for these factors. Moreover, mCD24 presented as a substrate binds to an unidentified receptor on postmitotic neurons and inhibits neurite outgrowth and branching (Shewan et al., 1996). In adult brain, mCD24 can also interact in trans with P-selectin expressed in endothelial cells (Aigner et al., 1997). Recently, the importance of vascular recruitment in adult neurogenesis has been shown, 

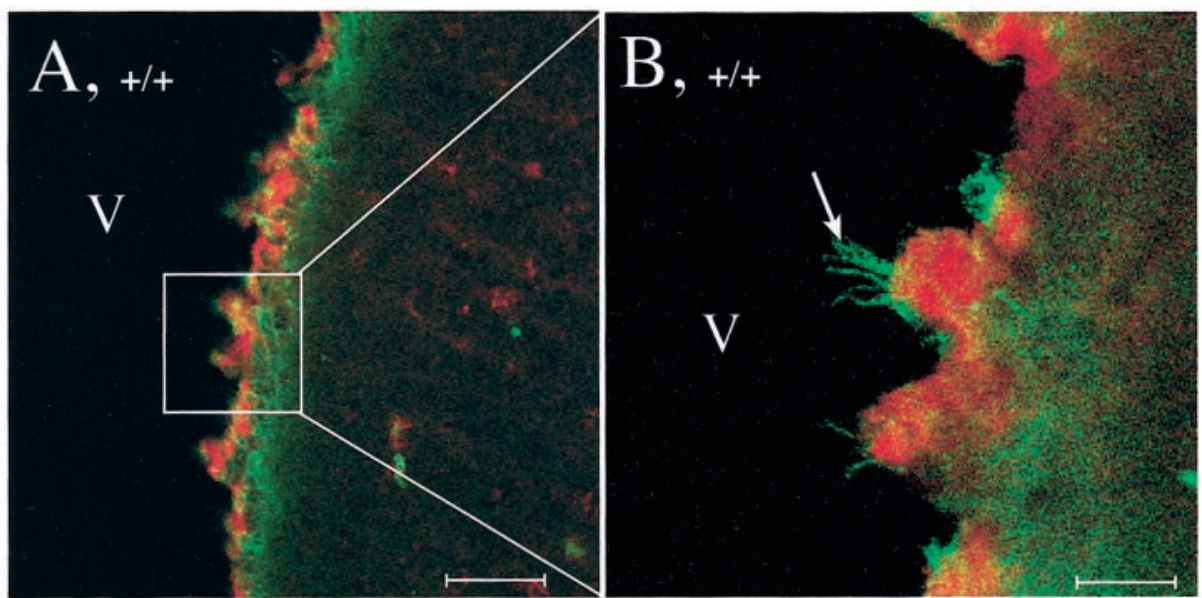

Figure 8. Slowly dividing cells are increased in both ependymal layer and SVZ in mCD24-/mice. $A$, Cells lining the lateral ventricle $(V)$ have their cytoplasm $\mathrm{S} 100+$ (red) and the membrane of their cilium labeled with mCD24 (green). Cells located in the SVZ are S100but $\mathrm{mCD} 24+$ (see enlargement in $B$ ). $C$, In WT mice, double labeling S100 (green) and BrdU (red) revealed that most of the slowly dividing cells are in the SVZ (arrows) and in a very few cases in the ependymal layer (see inset). $D$, In mCD24-/- mice, BrdU + nuclei (red) are localized, in majority, in the SVZ (single arrows). We can also observe S100+/BrdU+ cells in the ependymal layer (double arrows) (inset, mechanical separation of the ependyme from SVZ clearly showed this increase of the doublelabeled cells in the mCD24-/- ependymal layer). $E$, Differential quantification of slowly dividing cells in the ependymal layer $(E L)$ : even if the basal slow proliferation level is low in WT mice, it is significantly increased in the four selected ventricular levels in the mCD24-/- mice. In the SVZ, the percentage of slow proliferating cells is higher than those of the EL and in the four levels selected they are highest in the $\mathrm{mCD} 24-/-$ mice; the anterior part of the SVZ presents the highest proportion of BrdU+ cells $(* p<0.05 ; * * p<0.01$; *** $p<0.001)$. Scale bars: $A, D, 50 \mu \mathrm{m} ; B, 10$ $\mu \mathrm{m} ; C, 30 \mu \mathrm{m}$.
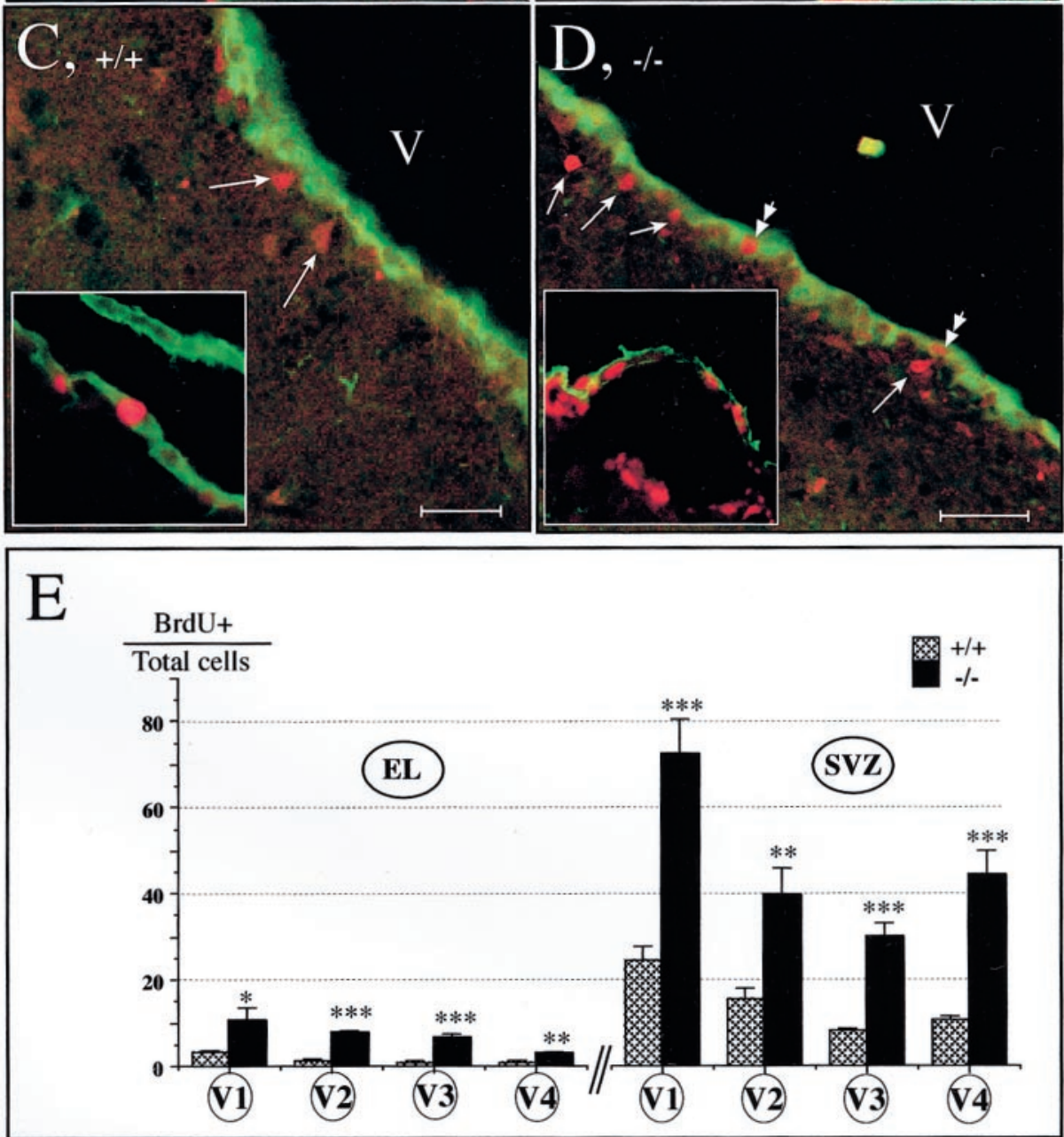

and it appears that neural proliferation occurs within an angiogenic niche (Palmer et al., 2000).

Even if proliferation of precursors occurs mainly in the SVZ, it is well shown that there is a persistent proliferation all along the RMS of normally expressing mCD24 cells. Under our experimental conditions, we did not observe an increased proliferation of these cells in the mCD24 mutant. We cannot exclude that the effect of mCD24 deletion differs according to the environment. This would not be unprecedented, because for example, TGF- $\alpha$ regulates the proliferation of only a subpopulation of progenitor cells in the dorsolateral corner of the adult subependyma, whereas its receptor is more widely expressed (Tropepe et al., 1997).

Whatever the mechanisms, our data make mCD24 an important cell surface molecule whose interactions influence cell cycle.

\section{Proliferation versus apoptosis in the mCD24 mutant mice}

Most of the dividing cells in the SVZ are generated to renew the granular and periglomerular neurons of the OB (Luskin, 1993). In WT adult mice, there is a strict regulation between input 

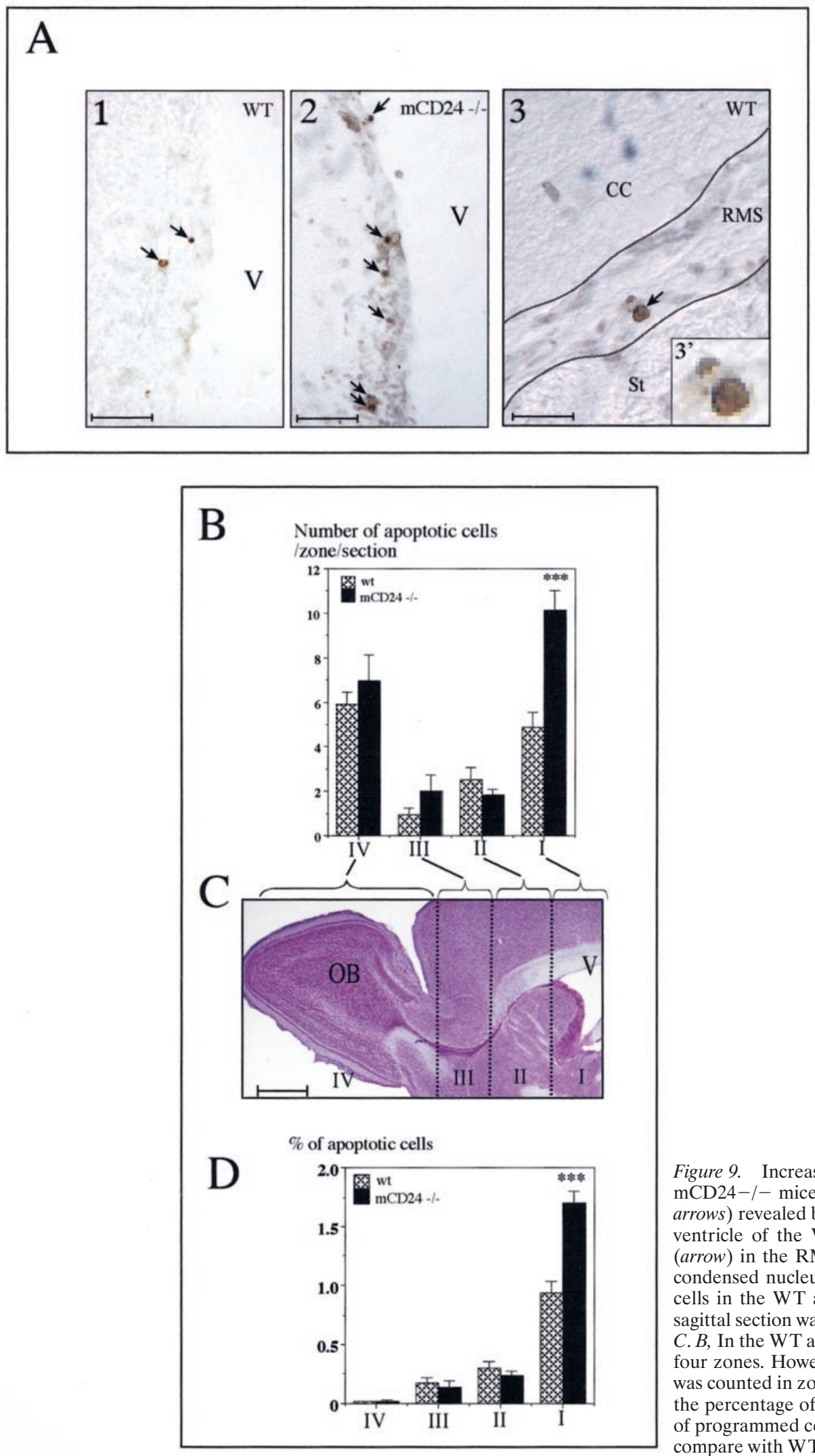

Figure 9. Increased apoptotic cells in the migratory pathway of the mCD24-/- mice. A1, A2, Examples of apoptotic nuclei (dark dots, arrows) revealed by the TUNEL technique in the SVZ of the lateral ventricle of the WT and mCD24-/- mice. A3, Apoptotic nuclei (arrow) in the RMS of WT mice (the enlargement in $3^{\prime}$ shows the condensed nucleus of the cell). For the quantification of apoptotic cells in the WT and mutant mice, the migratory pathway on each sagittal section was divided into four zones $(I-I V)$, as represented in $C . B$, In the WT and mutant mice, apoptotic cells were present in the four zones. However, in the mutant a higher number of dying cells was counted in zone I. This result was confirmed when we quantified the percentage of apoptotic cells $(D)$. There was a twofold increase of programmed cell death in the SVZ of mutant mice $(* * * p<0.001$ compare with WT). Scale bars: $A 1, A 2,100 \mu \mathrm{m} ; A 3,50 \mu \mathrm{m} ; C, 1 \mathrm{~mm}$.

(proliferation in the SVZ) and output (differentiation of interneurons in $\mathrm{OB}$ ). These regulations can occur at several levels: cell proliferation, PCD, migration, and terminal neuronal differentiation. Alteration of one of these components without compensa- tion by the others could result in a dramatic modification in the organization of the structure. This was observed for NCAM mutant mice, in which an alteration between migrating neuroblasts and their stationary environment created a reduction in $\mathrm{OB}$ 
size and a disturbance in laminar organization (Cremer et al., 1994; Gheusi et al., 2000).

In mCD24-deficient mice, in spite of an overproliferation of neuronal precursor cells in the SVZ and chain-like migrating neuroblast organization conserved, we did not find any significant increase in the size of mutant OB. However, we observed more TUNEL-positive cells in the mutant SVZ. Previous data showed that in WT mice, PCD occurs in SVZ and RMS (Brunjes and Armstrong, 1996; Biebl et al., 2000). PCD could even be the prominent fate of newly generated precursors, as suggested by Morshead and van der Kooy (1992). In the mCD24 mutant, supernumerary cells could undergo PCD because lack of mCD24 might perturb the coordination of events regulating the differentiation or counterbalance the overproliferation to conserve constancy in interneurons turnover. These adjusting events probably take place soon after cell proliferation. Even if apoptosis and proliferation imply different mechanisms and have their proper dynamics, evidence suggested that the two processes could be related. In fact, it has been well demonstrated that in these proliferative zones, PCD occurs not only in postmitotic neurons lacking neurotrophic factors but also in S-phase-labeled cells (Thomaidou et al., 1997; Blaschke et al., 1998). In addition, some of the molecules known to control cell proliferation (such as cyclin D1, p53, and E2F-1) are also activated during PCD as an indication of a molecular relationship between cell cycle and PCD (Ross, 1996). In many systems, the balance between cell cycle and PCD permits a continuous structural identity (Raff, 1996; Guo and Hay, 1999). Taken together, our results reflect such a property and point out the high capacity of the SVZ to modulate the final number of cells in OB. The mCD24 mutant model will be useful to separately study different components acting in synergy to control proliferation.

\section{REFERENCES}

Aigner S, Sthoeger ZM, Fogel M, Weber E, Zarn J, Ruppert M, Zeller Y, Vestweber D, Stahel R, Sammar M, Altevogt P (1997) CD24, a murin-type glycoprotein, is a ligand for P-selectin on human tumor cells. Blood 89:3385-3395.

Altman J (1969) Autoradiographic and histological studies of postnatal neurogenesis. 3. Dating the time of production and onset of differentiation of cerebellar microneurons in rats. J Comp Neurol 136:269-293.

Altman J, Das GD (1965) Post-natal origin of microneurons in the rat brain. Nature 207:953-956.

Amoureux MC, Cunningham BA, Edelman GM, Crossin KL (2000) N-CAM binding inhibits the proliferation of hippocampal progenitor cells and promotes their differentiation to a neuronal phenotype. J Neurosci 20:3631-3640.

Biebl M, Cooper CM, Winkler J, Kuhn HG (2000) Analysis of neurogenesis and programmed cell death reveals a self-renewing capacity in the adult rat brain. Neurosci Lett 291:17-20.

Blaschke AJ, Weiner JA, Chun J (1998) Programmed cell death is a universal feature of embryonic and postnatal neuroproliferative regions throughout the central nervous system. J Comp Neurol 396:39-50.

Brunjes PC, Armstrong AM (1996) Apoptosis in the rostral migratory stream of the developing rat. Brain Res Dev Brain Res 92:219-222.

Calaora V, Chazal G, Nielsen PJ, Rougon G, Moreau H (1996) mCD24 expression in the developing mouse brain and in zones of secondary neurogenesis in the adult. Neuroscience 73:581-594.

Chazal G, Durbec P, Jankovski A, Rougon G, Cremer H (2000) Consequences of neural cell adhesion molecule deficiency on cell migration in the rostral migratory stream of the mouse. J Neurosci 20:1446-1457.

Chen S, Bing R, Rosenblum N, Hillman DE (1996) Immunohistochemical localization of Lyn ( 556 ) protein in the adult rat brain. Neuroscience 71:89-100

Chiasson BJ, Tropepe V, Morshead CM, van der Kooy D (1999) Adult mammalian forebrain ependymal and subependymal cells demonstrate proliferative potential, but only subependymal cells have neural stem cell characteristics. J Neurosci 19:4462-4471.

Conover JC, Doetsch F, Garcia-Verdugo JM, Gale NW, Yancopoulos GD, Alvarez-Buylla A (2000) Disruption of Eph/ephrin signaling affects migration and proliferation in the adult subventricular zone. Nat Neurosci 3:1091-1097.
Craig CG, Tropepe V, Morshead CM, Reynolds BA, Weiss S, van der Kooy D (1996) In vivo growth factor expansion of endogenous subependymal neural precursor cell populations in the adult mouse brain. J Neurosci 16:2649-2658.

Cremer H, Lange R, Christoph A, Plomann M, Vopper G, Roes J, Brown R, Baldwin S, Kraemer P, Scheff S, et al (1994) Inactivation of the N-CAM gene in mice results in size reduction of the olfactory bulb and deficits in spatial learning. Nature 367:455-459.

Crispe IN, Bevan MJ (1987) Expression and functional significance of the J11d marker on mouse thymocytes. J Immunol 138:2013-2018.

Dehay, C Savatier, P Cortay, V Kennedy H. (2001) Cell-cycle kinetics of neocortical precursors are influenced by embryonic thalamic axons. J Neurosci 21:201-214.

Didier M, Harandi M, Aguera M, Bancel B, Tardy M, Fages C, Calas A, Stagaard M, Mollgard K, Belin MF (1986) Differential immunocytochemical staining for glial fibrillary acidic (GFA) protein, S-100 protein and glutamine synthetase in the rat subcommissural organ, nonspecialized ventricular ependyma and adjacent neuropil. Cell Tissue Res 245:343-351.

Doetsch F, Alvarez-Buylla A (1996) Network of tangential pathways for neuronal migration in adult mammalian brain. Proc Natl Acad Sci USA 93:14895-14900.

Doetsch F, Garcia-Verdugo JM, Alvarez-Buylla A (1997) Cellular composition and three-dimensional organization of the subventricular germinal zone in the adult mammalian brain. J Neurosci 17:5046-5061.

Doetsch F, Caille I, Lim DA, Garcia-Verdugo JM, Alvarez-Buylla A (1999) Subventricular zone astrocytes are neural stem cells in the adult mammalian brain. Cell 97:703-716.

Eriksson PS, Perfilieva E, Bjork-Eriksson T, Alborn AM, Nordborg C, Peterson DA, Gage FH (1998) Neurogenesis in the adult human hippocampus. Nat Med 4:1313-1317.

Figarella-Branger D, Moreau H, Pellissier JF, Bianco N, Rougon G (1993) CD24, a signal-transducing molecule expressed on human B lymphocytes, is a marker for human regenerating muscle. Acta Neuropathol 86:275-284.

Fischer GF, Majdic O, Gadd S, Knapp W (1990) Signal transduction in lymphocytic and myeloid cells via CD24, a new member of phosphoinositol-anchored membrane molecules. J Immunol 144:638-641.

Gheusi G, Cremer H, McLean H, Chazal G, Vincent JD, Lledo PM (2000) Importance of newly generated neurons in the adult olfactory bulb for odor discrimination. Proc Natl Acad Sci USA 97:1823-1828.

Gould E, Tanapat P, McEwen BS, Flugge G, Fuchs E (1998) Proliferation of granule cell precursors in the dentate gyrus of adult monkeys is diminished by stress. Proc Natl Acad Sci USA 95:3168-3171.

Guo M, Hay BA (1999) Cell proliferation and apoptosis. Curr Opin Cell Biol 11:745-752.

Hinds JW (1968) Autoradiographic study of histogenesis in the mouse olfactory bulb. I. Time of origin of neurons and neuroglia. J Comp Neurol 134:287-304.

Jankovski A, Sotelo C (1996) Subventricular zone-olfactory bulb migratory pathway in the adult mouse: cellular composition and specificity as determined by heterochronic and heterotopic transplantation. J Comp Neurol 371:376-396.

Johansson CB, Momma S, Clarke DL, Risling M, Lendahl U, Frisen J (1999) Identification of a neural stem cell in the adult mammalian central nervous system. Cell 96:25-34.

Kadmon G, Eckert M, Sammar M, Schachner M, Altevogt P (1992) Nectadrin, the heat-stable antigen, is a cell adhesion molecule. J Cell Biol 118:1245-1258.

Kadmon G, von Bohlen und Halbach F, Horstkorte R, Eckert M, Altevogt P, Schachner M (1995) Evidence for cis interaction and cooperative signalling by the heat-stable antigen nectadrin (murine CD24) and the cell adhesion molecule L1 in neurons. Eur J Neurosci 7:993-1004.

Kay R, Rosten PM, Humphries RK (1991) CD24, a signal transducer modulating $\mathrm{B}$ cell activation responses, is a very short peptide with a glycosyl phosphatidylinositol membrane anchor. J Immunol 147:1412-1416.

Kuchler S, Rougon G, Marschal P, Lehmann S, Reeber A, Vincendon G, Zanetta JP (1989) Location of a transiently expressed glycoprotein in developing cerebellum delineating its possible ontogenetic roles. Neuroscience 33:111-124.

Kuhn HG, Winkler J, Kempermann G, Thal LJ, Gage FH (1997) Epidermal growth factor and fibroblast growth factor-2 have different effects on neural progenitors in the adult rat brain. $\mathrm{J}$ Neurosci $17: 5820-5829$

Lois C, Alvarez-Buylla A (1993) Proliferating subventricular zone cells in the adult mammalian forebrain can differentiate into neurons and glia. Proc Natl Acad Sci USA 90:2074-2077.

Lois C, Garcia-Verdugo JM, Alvarez-Buylla A (1996) Chain migration of neuronal precursors. Science 271:978-981.

Luskin MB (1993) Restricted proliferation and migration of postnatally generated neurons derived from the forebrain subventricular zone. Neuron 11:173-189.

Menezes JR, Smith CM, Nelson KC, Luskin MB (1995) The division of 
neuronal progenitor cells during migration in the neonatal mammalian forebrain. Mol Cell Neurosci 6:496-508.

Morshead CM, van der Kooy D (1992) Postmitotic death is the fate of constitutively proliferating cells in the subependymal layer of the adult mouse brain. J Neurosci 12:249-256.

Morshead CM, Reynolds BA, Craig CG, McBurney MW, Staines WA, Morassutti D, Weiss S, van der Kooy D (1994) Neural stem cells in the adult mammalian forebrain: a relatively quiescent subpopulation of subependymal cells. Neuron 13:1071-1082.

Morshead CM, Craig CG, van der Kooy D (1998) In vivo clonal analyses reveal the properties of endogenous neural stem cell proliferation in the adult mammalian forebrain. Development 125:2251-2261.

Nedelec J, Pierres M, Moreau H, Barbet J, Naquet P, Faivre-Sarrailh C, Rougon G (1992) Isolation and characterization of a novel glycosylphosphatidylinositol-anchored glycoconjugate expressed by developing neurons. Eur J Biochem 203:433-442.

Nowakowski RS, Lewin SB, Miller MW (1989) Bromodeoxyuridine immunohistochemical determination of the lengths of the cell cycle and the DNA synthetic phase for an anatomically defined population. J Neurocytol 18:311-318.

Nielsen PJ, Lorenz B, Muller AM, Wenger RH, Brombacher F, Simon M, von der Weid T, Langhorne WJ, Mossmann H, Kohler G (1997) Altered erythrocytes and a leaky block in B-cell development in CD24/ HSA-deficient mice. Blood 89:1058-1067.

Palmer TD, Willhoite AR, Gage FH (2000) Vascular niche for adult hippocampal neurogenesis. J Comp Neurol 425:479-494.

Pardee AB (1989) G1 events and regulation of cell proliferation Science 246: 603-608.

Raff MC (1996) Size control: the regulation of cell numbers in animal development. Cell 86:173-175.

Ross ME (1996) Cell division and the nervous system: regulating the cycle from neural differentiation to death. Trends Neurosci 19:62-68.

Rougon G, Dubois C, Buckley N, Magnani JL, Zollinger W (1986) A monoclonal antibody against meningococcus group B polysaccharides distinguishes embryonic from adult N-CAM. J Cell Biol 103:2429-2437.

Rougon G, Alterman LA, Dennis K, Guo XJ, Kinnon C (1991) The murine heat-stable antigen: a differentiation antigen expressed in both the hematolymphoid and neural cell lineages. Eur J Immunol 21:1397-1402.
Sasaki K, Kurose A, Ishida Y (1993) Flow cytometric analysis of the expression of PCNA during the cell cycle in HeLa cells and effects of the inhibition of DNA synthesis on it. Cytometry 8:876-882.

Shewan D, Calaora V, Nielsen P, Cohen J, Rougon G, Moreau H (1996) $\mathrm{mCD} 24$, a glycoprotein transiently expressed by neurons, is an inhibitor of neurite outgrowth. J Neurosci 16:2624-2634.

Shirasawa T, Akashi T, Sakamoto K, Takahashi H, Maruyama N, Hirokawa K (1993) Gene expression of CD24 core peptide molecule in developing brain and developing non-neural tissues. Dev Dyn 198:1-13

Stefanova I, Horejsi V, Ansotegui IJ, Knapp W, Stockinger H (1991) GPI-anchored cell-surface molecules complexed to protein tyrosine kinases. Science 254:1016-1019.

Thomaidou D, Mione MC, Cavanagh JF, Parnavelas JG (1997) Apoptosis and its relation to the cell cycle in the developing cerebral cortex J Neurosci 17:1075-1085.

Tropepe V, Craig CG, Morshead CM, van der Kooy D (1997) Transforming growth factor-alpha null and senescent mice show decreased neural progenitor cell proliferation in the forebrain subependyma. J Neurosci 17:7850-7859.

Wang C, Rougon G, Kiss JZ (1994) Requirement of polysialic acid for the migration of the O-2A glial progenitor cell from neurohypophyseal explants J Neurosci 14:4446-4457.

Wang QM, Studzinski GP, Chen F, Coffman FD, Harrison LE (2000) p53/56(lyn) antisense shifts the 1,25-dihydroxyvitamin D3-induced G1/S block in HL60 cells to $\mathrm{S}$ phase. J Cell Physiol 183:238-246.

Wenger RH, Ayane M, Bose R, Kohler G, Nielsen PJ (1991) The genes for a mouse hematopoietic differentiation marker called the heat-stable antigen. Eur J Immunol 21:1039-1046.

Wichterle H, Garcia-Verdugo JM, Alvarez-Buylla A (1997) Direct evidence for homotypic, glia-independent neuronal migration. Neuron 18:779-791.

Zarn JA, Zimmermann SM, Pass MK, Waibel R, Stahel RA (1996) Association of CD24 with the kinase c-fgr in a small cell lung cancer cell line and with the kinase lyn in an erythroleukemia cell line. Biochem Biophys Res Commun 225:384-391.

Zigova T, Pencea V, Wiegand SJ, Luskin MB (1998) Intraventricular administration of BDNF increases the number of newly generated neurons in the adult olfactory bulb. Mol Cell Neurosci 11:234-245. 